\title{
La música en
}

\section{éxtasis en el teatro \\ de Carles Santos}

Music in Ecstasy in Carles Santos' Theater

Jolanta Rȩkawek

Recebido em: 26 de dezembro de 2020

Aceito em: 26 de janeiro de 2021
Es escritora polaca, Doctora en Filología Española, Moderna y Latina por la Universidad de las Islas Baleares (España), Post-doctora por el Departamento de Historia del Arte de la Universidad de Barcelona (España). Es profesora plena en la Universidad Estadual de Feira de Santana, en Brasil, donde coordina el Núcleo de Estudios de Espectacularidad desarrollando los estudios sobre la memoria como una marca de la contemporaneidad, el cuerpo transcultural puesto en escena y nuevas perspectivas de la literatura y del arte. Contato: jolantaion@gmail.com Brasil 
PALABRAS CLAVE:

música, teatro, asombro, experiencia, Carles Santos.

KEY WORDS: music, theater, amazement, experience, Carles Santos.
Resumen: Este artículo se propone dar a conocer la obra teatral de Carles Santos -músico español, oriundo de la Comunidad Valenciana, que se convirtió en una referencia de la cultura universal y que a pesar de ello cuenta con escasa bibliografía académica que trate de su legado. El objetivo de este trabajo es destacar la importancia del arte de Santos para la sociedad tardo-moderna, analizada por el filósofo Byung-Chul Han que la define como una sociedad de rendimiento y en la que observa la hipertrofia de la positividad en detrimento de la negatividad y del asombro que son premisas fundamentales para tener experiencias. En el contexto de la sociedad del rendimiento, que nos priva de experiencias, abordamos la propuesta artística de Santos que consiste en crear el teatro a partir de la música dando origen a una forma híbrida que acabó consagrándole como un creador teatral que proporcionaba al público la oportunidad de cultivar la capacidad de asombrarse y así poder tener experiencias a través del teatro.

Abstract: This article aims to publicize the theater of Spanish musician Carles Santos - a native of the Valencian Community who has become a reference for universal culture despite there being little academic attention to his legacy. The objective is to highlight the importance of Santos's art for late-modern society, as analyzed by the philosopher Byung-Chul Han, who defines it as a society of productivity in which he observes the hypertrophy of positivity to the detriment of the negativity and amazement that are fundamental premises for having experiences. In the context of the performance society, which deprives us of experiences, we approach Santos's artistic proposal, which consisted of creating theater from music, giving rise to a hybrid form that ended up establishing him as a theatrical creator who provided the public with the opportunity to cultivate the ability to be amazed and thus have experiences through theater. 
Para la desesperación de su familia que formaba parte de la élite de Vinaròs, una pequeña ciudad en la Comunidad Valenciana en España, Carles Santos (1940-2017)) se negó a ser un virtuoso del piano y decidió tomar las riendas de su destino convirtiéndose en una de las mayores referencias de la vanguardia artística en España y en el mundo. A pesar de su relevancia la bibliografía académica que trata de su obra es escasa y, por tanto, este trabajo tiene como objetivo contribuir para ampliar los estudios sobre la obra de uno de los artistas más polifacéticos e significativos para la cultura del siglo XX y XXI.

Ni los padres de Santos ni el cura, que le enseñaba la estructura de una fuga, jamás habrían imaginado qué rumbo iba a tomar la relación del pequeño Carles con el piano. El artista comentaba el vínculo con su instrumento de la manera siguiente:

Lo más habitual es que los pianistas mantengan con sus pianos una constante relación de infidelidad y promiscuidad. Yo quiero ser fiel a mi piano porque tardé 50 ańos para percibir que tener un buen instrumento en casa influencia de una manera esencial la composición y, además de esto, un piano tan grande como éste ${ }^{1}$ te obliga a vivir con él una auténtica relación de pareja. No se debe perder esta relación visceral, física, sensual, erótica e incluso pornográfica” (Ruvira, 1996, 26).

1 Un Bösendorfer Imperial. 


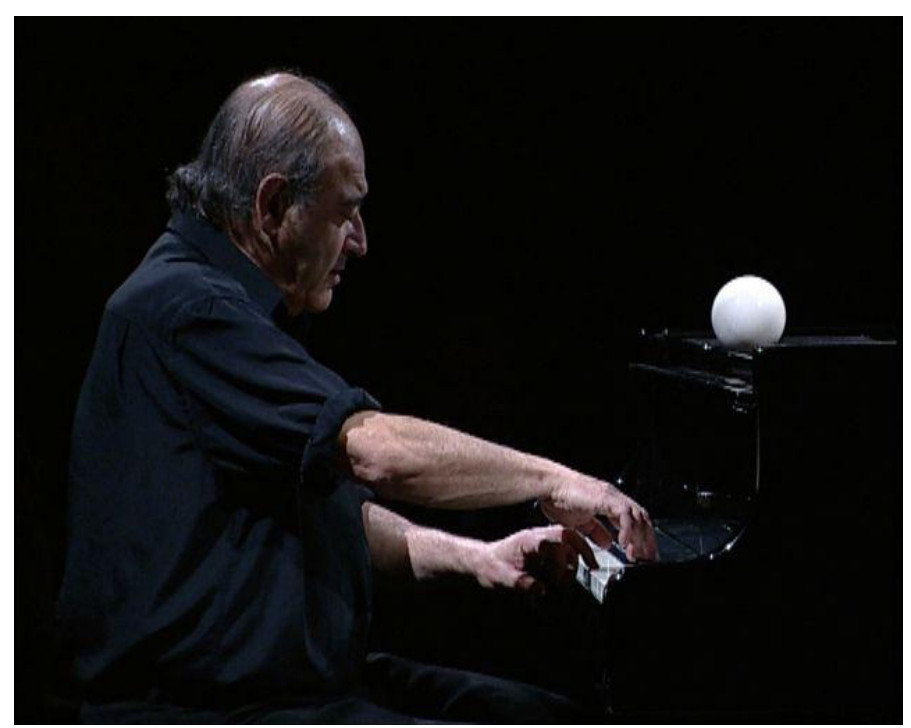

Figura 1: Carles Santos. El concierto en Vinaròs.

Fuente: Fundació Vinaròs, el archivo personal del artista. ${ }^{2}$

A pesar de haber perfeccionado su técnica como pianista a través de una rígida disciplina del conservatorio Carles Santos nunca ha perdido el gusto por componer y tocar. Comenzaba el día tocando Bach, que era su compositor predilecto, y disfrutaba mucho al presentarse en los conciertos en público que consideraba como una forma sublime de comunicar.

La música nos da una gran satisfacción, ella no nos dice lo que tenemos que hacer o dejar de hacer, no nos obliga a nada, simplemente a disfrutarla. Creo que por detrás de todo eso hay una teoría del placer más o menos

2 Todas las fotos exhibidas en el artículo están cedidas por la Fundació Vinaròs que retiene los derechos del autor de Carles Santos. Queremos manifestar nuestra gratitud a la Fundación Vinaròs por preservar y hacer accesible el legado del artista. 
estudiada, o una fuente de placer. La música es muy sensual. Es un tipo de placer incontrolable (Santos, 1999, 184). ${ }^{3}$

Esta “teoría del placer" le servía a Santos como punto de partida para formular su propuesta artística que transgredía el pensamiento convencional circulando libremente por varios campos del arte como la música, el teatro, la performance, el cine, la fotografía, las artes plásticas y la literatura. Su natural tendencia a desplazarse del ámbito de lo obvio le llevó a buscar inspiración en la música dodecafónica de la Segunda Escuela de Viena representada por Arnold Shoenberg, Alban Berg y Anton Webern. Su estancia en Nueva York en 1967 y sus retornos a esta ciudad en la década siguiente le proporcionaron la oportunidad de ver surgir el movimiento Fluxus y familiarizarse con las aportaciones de los músicos como John Cage, Steve Reich o La Monte Young que solía componer piezas con una sola nota. Incluso se pueden encontrar coincidencias entre la obra de Santos y la música de Frank Zappa apuntadas por Aurora Marín en su Trabajo Final del Grado en Historia del Arte en la Universidad de Barcelona que son de carácter artístico y vital y que tendrían un denominador común: la heterodoxia y la iconoclastia $(2019,30)$.

Aquellos contactos de Santos con las vanguardias rindieron frutos en las composiciones y acciones performáticas del artista como, por ejemplo, Minimalet sur mer $(1988)^{4}$, en la que Santos tocaba el piano en alta mar. En

3 In: “Carles Santos. Catálogo de la exposición”. Castellón: Espai de l’Art Contemporani de Castellò, 25/05 - 05/1, 1999.

4 Disponible en: https://www.youtube.com/watch?v=P0d2AQHScss. Acceso el 24/01/2021 
otra acción llamada Anem, anem, anem a volar (1982) el artista empujaba por las principales avenidas de Barcelona un piano de cola con una soprano tendida encima de él.

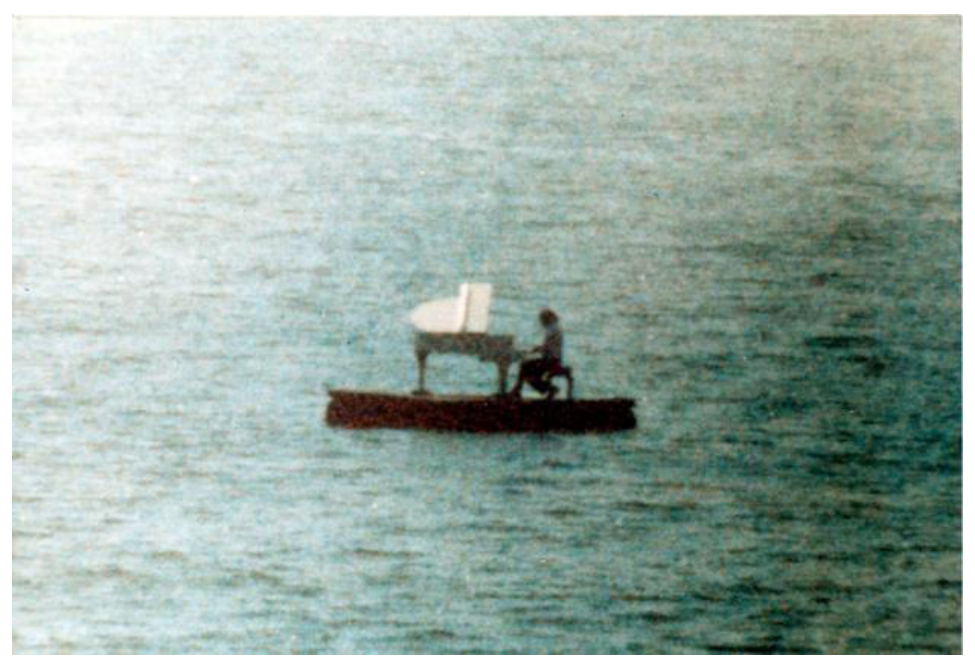

Figura 2: Carles Santos en Minimalet sur mer (1988).

Fuente: Fundació Vinaròs, el archivo personal del artista.

Décadas después, en 2014, el público, que acudió a la presentación de su disco Lo bo ve per baix en el Centro de Arte Santa Mónica en Barcelona, pudo comprobar que su espíritu de vanguardia estaba muy vivo. Para la sorpresa de varios participantes de aquel evento el músico frustró la expectativa de interpretar sus composiciones al piano y permaneció tumbado en la entrada

5 Disponible en: https://vimeo.com/404575588. Acceso el 24/01/2021. 
haciendo que el público tuviera que pasar por encima de su espalda para poder adentrar en el recinto. ${ }^{6}$ La música fue emitida por un ordenador.

Cabe señalar que una parte significativa de la vasta obra de Carles Santos ha sido catalogada por Joaquin Ortells que en 2015 presentó la tesis de doctorado en la Universidad Jaume I de Castellón, en la que ha distinguido varios géneros: obra pianística, obra vocal, obra para voz y piano, obra instrumental, obra de otras agrupaciones (desde dúos a diversas masas instrumentales o vocales) y obra escénica.

\section{LA INCERTIDUMBRE AVANZA}

El asombro que debió de sentir más de un espectador desprevenido en el evento mencionado antes podría compararse con el del público que en 1947 vio la pieza Sord-mut de Joan Brossa (1919-1998), poeta y dramaturgo que introdujo las segundas vanguardias en Cataluña. En aquella acción Brossa mostró durante varios minutos un escenario en blanco sin que nada pasara en él7. Su intención, que se había adelantado a Silence (1962) de John Cage, era desconcertar al público que no estaba acostumbrado al silencio ni a la ausencia de acción expuestos en un escenario.

6 Link: https://www.youtube.com/watch?v=I3IKLA4T054. Carles Santos presenta su último disco "Lo bo ve per baix" en el Centro de Arte Santa Mónica en Barcelona. Acceso el 24/01/2021.

7 Se puede ver el fragmento de aquella pieza en el reportaje televisivo "La culpa fue de Joan Brossa" de TVE. Disponible en: https://www.youtube.com/watch?v=kY4106zKmTc\&t=319s. Acceso el $24 / 01 / 2021$. 
$\mathrm{Al}$ tener el contacto diario con Brossa durante 5 años, Carles Santos aprendió que tocar el piano no era suficiente para ser artista. En la perspectiva vanguardista del arte que profesaba Brossa, la música podría ser mucho más que el sonido, podría invadir de una manera imprevisible el campo de la acción y de la imagen modificando sus habituales funciones en el arte. Santos aprendió aquella lección y confrontó la evidencia en el arte articulando las posibilidades nunca vistas de los recursos utilizados por él en el proceso creativo. Arremeter contra la evidencia se convirtió en el lema de Santos, expuesto en su texto llamado Evidencia, publicado en el libro Textos escabetxats:

[ ] LA CREACIÓN COMO FORMA DE EXPRESIÓN Y COMUNICACIÓN HA DE SER CREATIVA.

DECIR QUE LA CREACIÓN HA DE SER CREATIVA ES UNA REDUNDANCIA.

LA REDUNDANCIA POR SU OBVIEDAD ES DESEFICAZ Y NO TIENE CAPACIDAD CREATIVA.

(O ¿PUEDE SER QUE SI?)

[...]

LA REDUNDANCIA SE REVOLTA EN LA EVIDENCIA Y PRODUCE DESINTERÉS.

[...]

EL CONCEPTO DE OBVIEDAD COMO EL DE LA REDUNDANCIA NO GENERAN, OBVIAMENTE, ESPECTATIVAS DE CREACIÓNPOSITIVA SINO TODO AL CONTRARIO: LA DES-CREACIÓN.

[...]

PERSISTE LA OBSESIÓN POR LA REDUCCIÓN Y LA BÚQUEDA DE CONCEPTOS VACÍOS E INÚTILES, TAN INÚTILES COMO LA REDUNDANCIA, QUE FINALMENTE REDUNDA SOBRE ELLA MISMA.

SIGUIENDO EN ESTA DIRECCIÓN LA ESCRITURA PUEDE CONVERTIRSE EN INVISIBLE, VACIÁNDOSE DE UN CONTENIDO APARENTE: ESCRITURA DES-ESCRITA. 
[...]

AQUEL DESEO DE VACIAR DE CONTENIDO UTILIZANDO OTROS CONTENIDOS ES UNA REDUNDANCIA INEVITABLE Y, DE ALGUNA MANERA, LLENA DE CONTENIDO. [...]

DEJAR DE HACER ALGO, SEGÚN CÓMO, PUEDE SER MÁS IMPORTANTE COMO CONCEPTO QUE HACERLO. A PARTIR DE ESTE MOMENTO TODO ES RELATIVO Y ALGUIEN, NI MUY VIEJO NI MUY JOVEN, DICE UNA PALABRA TAN MACHACADA E INESPERADA COMO “VANGUARDIA" (2006, 92-93).

Con esta apología de la insensatez que confronta la razón en el proceso creativo, Santos nos adelanta su estrategia de driblar el habitual rol de la música como transmisora del sonido para atribuirle nuevas facultades en el teatro. De hecho, la música no apenas interpretada sino visualizada en el escenario con nuevas potencialidades es la propuesta que le ha dado más prestigio y fama concretizándose al final de los 80 cuando Santos adoptó el teatro como su principal forma de expresión artística.

"Necesito un abogado" - esta frase proviene de Patetisme il.lustrat ${ }^{8}$ - su última obra teatral, iniciada con una letanía de improperios que Santos debió haber oído en su larga vida de creador. Confrontar al espectador con las situaciones escénicas que se disparaban en función de un pensamiento heterodoxo, era el claro legado de Joan Brossa que Santos aprovechó, por ejemplo, en su espectáculo Brossalobrossotdebrossat (2008) homenajeando a su amigo. Al componer el juego escénico que desafiaba la lógica de causa - efecto, el artista ha involucrado a

8 Todas las obras teatrales de Carles Santos, mencionados en este artículo, fueron analizadas con base en los registros archivados en el Teatre Nacional de Catalunya y en el Teatre Lliure. 
los cuatro intérpretes en diálogos y situaciones insólitas como aquella en la que una intérprete se sienta al piano con la partitura abierta y toca apenas una sola nota. Seguidamente aparece con una partitura en blanco, sin ninguna nota, que pone delante de sus ojos al sentarse al piano y sin mirarla se vuelca en una interpretación descontrolada, llena de pasión. ${ }^{9}$

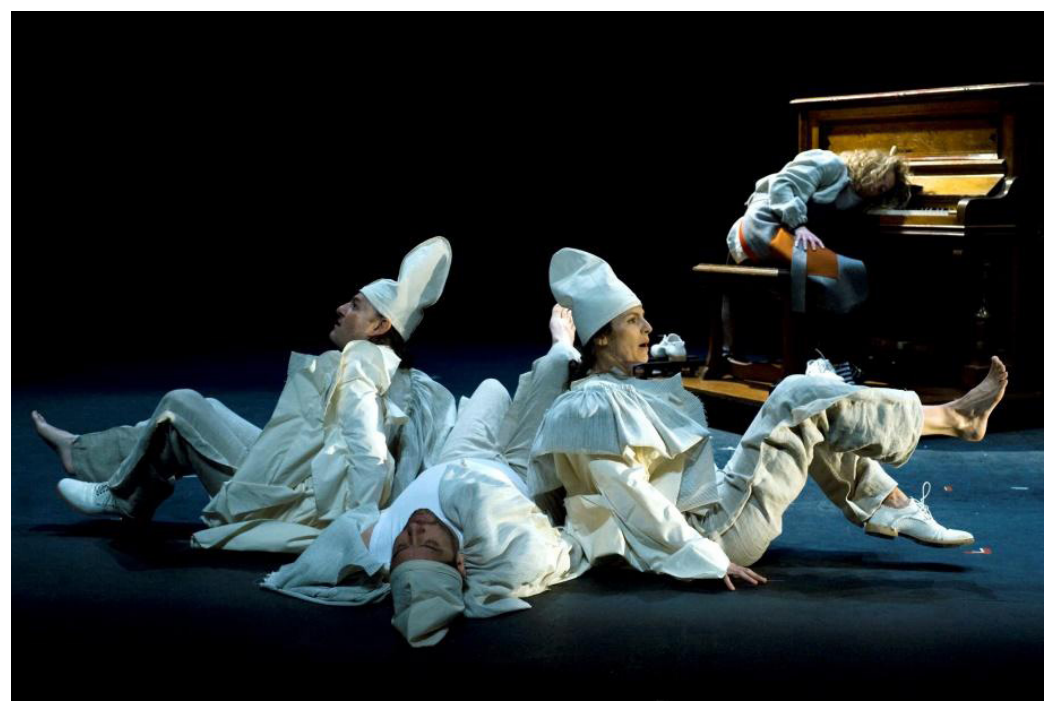

Figura 3: Brossalobrossotdebrossat (2008).

Fuente: Fundació Vinaròs, el archivo personal del artista.

La idea clave del arte de Santos era crear situaciones insólitas en el escenario otorgando el poder absoluto a la música que da origen a una obra híbrida, en la que confluyen varios lenguajes artísticos inundando el

9 Disponible en: https://www.youtube.com/watch?v=jI3WZaKtKjs\&list=RDjI3WZaKtKjs\&index=1. Acceso el 24/01/2021. 
teatro con imágenes que impactan al público. El mismo Santos describía su propuesta artística de la manera siguiente:

\begin{abstract}
Mi práctica se fomenta, por una parte, por medio de un código austero en el cual se desenvuelve un concierto tradicional y, por otra, la experiencia acumulada durante ańos de trabajar dentro de la vanguardia musical de los últimos años. Más allá de la decodificación o la deconstrucción del lenguaje musical lo que me interesa es la construcción ( ) de un lenguaje personal que llegue polivalentemente a dar golpes al auditorio sin utilizar elementos efectistas y, por tanto, manipuladores. La inter-relación que sobre la base de la especificidad musical efectúo por medio de diversos medios semióticos (música, piano, canto, gesto, etc.), produce una estructura difícil de catalogar, pero en la cual las partes son inseparables y donde el factor determinante es mi actitud delante del fenómeno musical (Ruvira, 1996, 38).
\end{abstract}

Santos tenía un don especial para incentivar al actor o cantante que se veía capaz de actuar en el escenario utilizando no solamente la voz, sino apropiándose de sus habilidades que ni siquiera había intuido hasta entonces. Las escenas creadas en sus espectáculos requerían una sólida preparación física por parte de los intérpretes que tenían que complementar su destreza vocal asumiendo una nueva función que podría llamarse la función de poliactuantes y que sería una forma híbrida entre actores, cantantes y acróbatas dispuestos a ponerse a las órdenes de un creador valiente. "Incluso he de retener el impulso porque yo iría más lejos" - comentaba Santos $(2014)^{10}$ refiriéndose a sus visiones puestas en escena.

10 En la entrevista "Val la pena saber el que no podem saber?" realizada con Carles Santos por Jolanta Rękawek y Enric Ciurans. Barcelona: Universitat de Barcelona, 02/06/2014, disponible en el archivo de los autores y también en la Fundació Vinaròs. 
Movilizando a los intérpretes para que accionen el cuerpo y la voz como fuentes de posibilidades infinitas, Santos configuraba la escena teatral apelando a los sentidos del actuante y del espectador. Avanzaba hacia el público como un visionario intensificando la secuencia de imágenes, sonidos, gestos y lo que él llamaba de des-escritura, es decir el texto escénico imposible de ser descifrado a través de la comprensión racional. "De un texto me interesa más contar, pesar y medir sus componentes que los contenidos tradicionales" - dice un personaje en Pentagrama o esperma? (Santos, 2006, 22). Para el artista, el texto era una potencia sonora. "[ ] yo creo que un texto es una partitura. Al revés no. Y un actor es un músico. A pesar de que cuando empiezo a construir una obra, escribo mucho. Y los mismos textos me llevan hacia la música” (2014).

Oscilando entre varios géneros artísticos Santos no pretendía ganarse una etiqueta de "transgresor" que le habían puesto sus detractores sin entrar en el mérito de su arte. Su única pretensión era poder comunicar apostando no tanto por el gusto refinado del espectador sino por su sensibilidad, por su conexión con la emoción y su capacidad de asombrarse. Así comentaba el artista su expectativa con respecto al público que iba a ver sus espectáculos:

Lo mejor es que no sepa nada. Lo mejor es crear situaciones y si alguien quiere profundizar, pues de acuerdo. Y lo que vaya adquiriendo que lo adquiera en función de lo que ve, de lo que siente, de lo que lee. Creo que lo más sencillo es llegar a un lugar y plantear una situación (ibídem).

Su relación con el espectador consolidada por una propuesta que descartaba cualquier tipo de elementos superfluos de fácil impacto, le proporcionó una 
fama internacional y un aprecio del público fiel que acompañaba los estrenos de sus espectáculos con entusiasmo.

\section{LA POTENCIA DEL ASOMBRO}

Un buen ejemplo de ello es su obra Sama Samaruck Suck Suck (2002) estrenada en el Théâtre Paris-Villette, resumida por Santos como "un sueño sin gravedad" $(2006,146)$ y definida como una ópera escondida dentro de la estructura del circo (2014). Para Santos, era fundamental percibir primero la diferencia entre estos dos géneros artísticos para crear seguidamente una estructura híbrida que conllevaba una indagación filosófica.

La ilusión, la alegría, la angustia, el miedo, el riesgo, el drama, la fiesta, el misterio, la fascinación, lo imposible, lo irreal. Todo esto, y más, es el gran ritual del circo que todos compartimos desde siempre como un patrimonio común.

$[\ldots]$

Detrás de esta red codificada de sueńos y de ilusiones, de alguna manera previsibles, debe existir otra trama de sueños e ilusiones que nunca se han enfrentado con la gravedad ni se han medido dentro de la carpa.

El sueño del sueño, la ilusión desconocida, el secreto no compartido, el miedo real, el riesgo inédito, la alegría retenida, la fiesta solitaria, el rechazo. Todo esto, y muchas más cosas, no forman parte del ritual circense y, por tanto, no lo compartimos como un patrimonio común (Santos, 2006, 146).

Esta medida de fuerzas entre el lenguaje circense y el operístico exploraba el factor del riesgo real pues hacer un espectáculo circense, regido por una partitura musical, era muy peligroso porque significaba hacer algo que ni Santos ni sus intérpretes sabían hacer. Los cantantes de ópera tenían que 
tirarse al aire enganchados por un cable y al mismo tiempo ejecutar una partitura musical cantando y afinando. Santos explicaba que hubo un natural deslizamiento de fronteras entre los representantes de diferentes géneros artísticos: los cantantes aprendieron a mover su cuerpo en el espacio de la manera que nunca lo habían hecho antes y los acróbatas se apropiaron de su voz como herramienta válida para actuar en el escenario. ${ }^{11}$

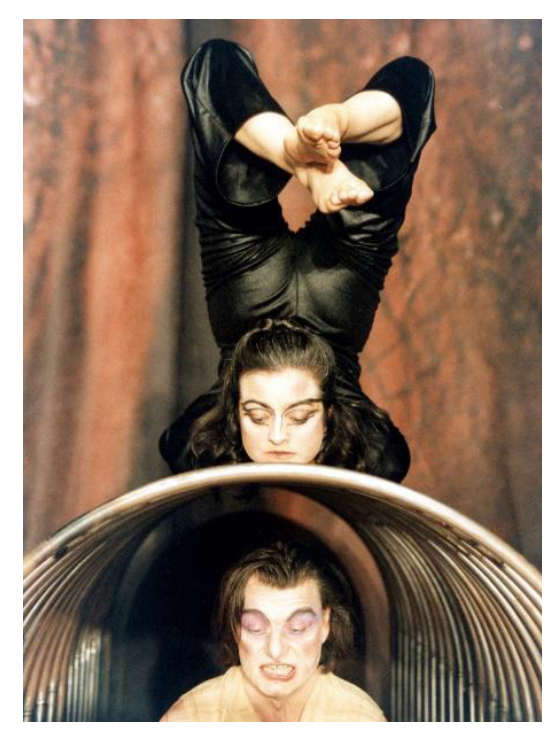

Figura 5: Sama Samaruck, Samaruck Suck Suck (2002).

Fuente: Fundació Vinaròs, el archivo personal del artista.

Los cantantes de ópera volaban en el aire colgados de una cuerda o circulaban montados en bicicletas mientras los acróbatas pronunciaban

11 Link: https://www.youtube.com/watch?v=qpNYppyVPdM. Acceso el 25/01/2021. 
monólogos contorsionándose o escalando una pared. De aquel espectáculo, que indagaba en la necesidad humana de saber, de elucidar misterios, emanaba una potente dosis de peligro implícita en el acto vital del ser humano de tomar conciencia de algo. " ¿Vale la pena saber lo que no podemos saber?" - preguntaba una contorsionista adoptando una posición inviable para una persona común. Y un acróbata, que escalaba la pared, decía un monólogo sobre el peligro de saber y de caer al mismo tiempo. En aquella obra arriesgada y leve como los cuerpos de sus intérpretes que parecían circular en un espacio sin gravedad, Santos se preguntaba sobre la avidez del ser humano de conquistar la altura, el conocimiento, la sabiduría que podría llevar a la muerte tras una caída.

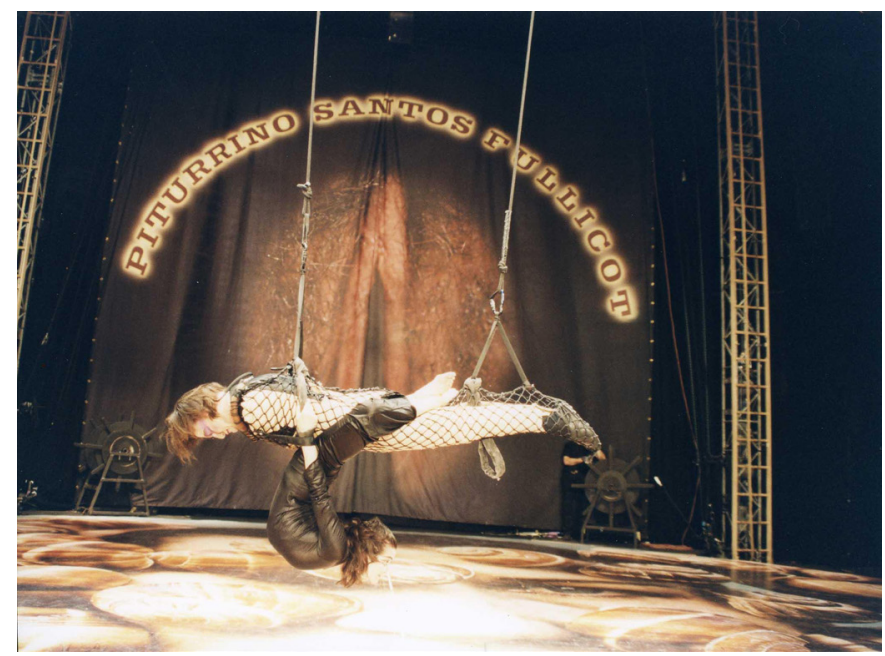

Figura 6: Sama samaruck samaruck suck suck.

Fuente: Fundació Vinaròs, el archivo personal del artista. 
La indagación filosófica planteada en aquella obra no necesitaba un texto dramatúrgico para articularse. Todos los recursos estaban bajo las órdenes de la música. De modo que la reacción del público no podía limitarse al ámbito del agrado apenas sino que fluctuaba naturalmente hacia un sentimiento no verbalizado de asombro. Los espectadores salían de aquel espectáculo estremecidos, desprovistos de su hábito de descodificar racionalmente una obra de arte, pues intentar hacerlo resultaba ser una misión imposible.

La extrañeza patente en la reacción del público delante de los espectáculos de Santos puede llevarnos a una reflexión sobre la importancia del asombro que provoca el arte que mantiene un vínculo natural con la negatividad, entendida por uno de los más perspicaces estudiosos de la sociedad en que vivimos - el filósofo Byung-Chul Han, como el encuentro con lo distinto. Han recuerda la idea de Gadamer de que la negatividad es el elemento constituyente del arte, "es su herida" (2018a, 17) y también remite al pensamiento de Adorno, para el cual el arte debe provocar la extrańeza. "Para Adorno no habría ningún arte que haga sentirse a gusto. La extrañeza es inherente incluso al espíritu” (2018, 96).

El filósofo analiza la hipertrofia de la positividad en la sociedad del siglo XXI, definida por él como la sociedad del rendimiento, que disipa cualquier rastro de lo distinto y crea una ilusión de un mundo liso, sin obstáculos, en el cual prima lo igual imponiéndonos la aspiración a parecernos unos a los otros. La eliminación de lo negativo tiene efectos atroces, según Han, en la medida en que nos priva de experiencias que solamente podríamos tener enfrentando la alteridad. La alteridad, en principio, no nos agrada, 
nos estremece. La disposición a procesar la extrañeza como la reacción delante de lo distinto nos brinda la oportunidad de tener experiencias que naturalmente llevan a la transformación del ser humano. Perder la capacidad de asombrarse significa perder la oportunidad de tener experiencias y esta pérdida de la capacidad de conmoción y extrañeza está apuntada como una tendencia alarmante por Byung-Chul Han que alerta sobre la reducida gama de experiencias en la sociedad en que vivimos. "La sociedad ha perdido toda la alteridad, toda la extrañeza” (Idem., 95).

En el contexto de las reflexiones de Han la obra artística de Carles Santos, que mediante la ruptura con los códigos convencionales de representación provoca la extrañeza en el público llevándole al encuentro con una forma teatral distinta, adquiere una importancia fundamental hoy en día en la medida en que propicia el cultivo de la capacidad del asombro, estremece al espectador dejándole una vía libre hacia la posibilidad de tener experiencias a través del teatro.

\section{Vía LIBRE HACIA LA fantASíA}

Una de las experiencias más significativas en este sentido fue el espectáculo Ricardo y Elena (2000) que era una ópera cantada en latín inspirada en los padres de Santos que después de la Guerra Civil Española (1936-1939) acataron las normas de la vida típica de una familia acomodada en una ciudad de provincias. El espectáculo era compuesto por un conjunto de recursos 
híbridos que ponían en evidencia una memoria adulterada, manipulada, con la que Santos quiso reconstruir mágicamente una época.

Ricardo y Elena eran mis padres. [ ] Y al tratar de rescatarlos al teatro de alguna manera todo sonaba en latín. [ ] El latín para la música es buenísimo, suena de una manera extraordinaria. Y toda la obra tenía muchas personas pero sobre todo era un problema musical, la sonoridad, la utilización de la boca de mis padres que me sonaba así (Santos, 2014).

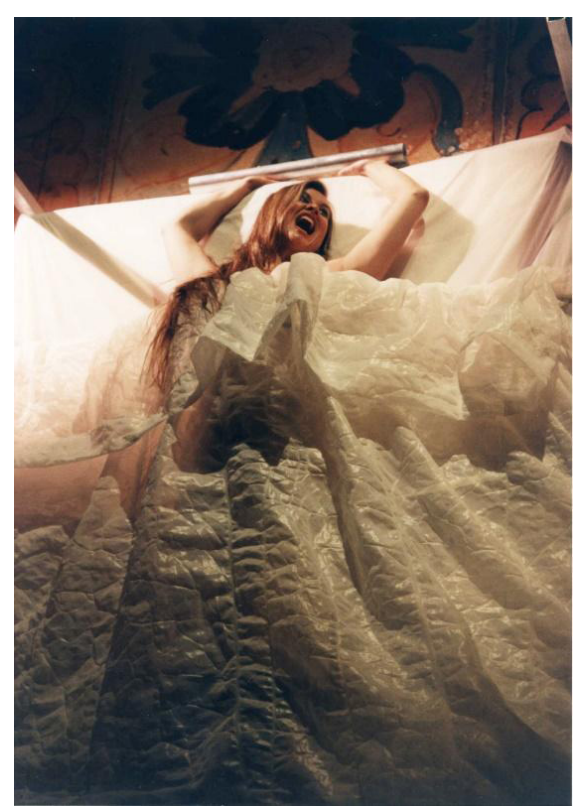

Figura 7: Ricardo y Elena (2000).

Fuente: Fundació Vinaròs, el archivo personal del artista.

La secuencia de imágenes insólitas como el parto de su madre, Elena, representado por una cantante en una cama colgada verticalmente como una 
pared, el nacimiento de Santos que salía desde dentro de un piano como si fuera el vientre de su genitora, el martirio de su padre, Ricardo, agarrado a una barra cambiando camisas como si fuera un reptil cambiando de piel, el coito entre Santos y su piano, encarnado por una bailarina lasciva ${ }^{12}$, la caída de una enorme cruz sobre el escenario, no es una especie de autobiografía de Carles Santos. En aquella obra el artista recurre al pasado que altera a su antojo, sintiendo un verdadero placer de evocar lo que parecía haberse ido ya.

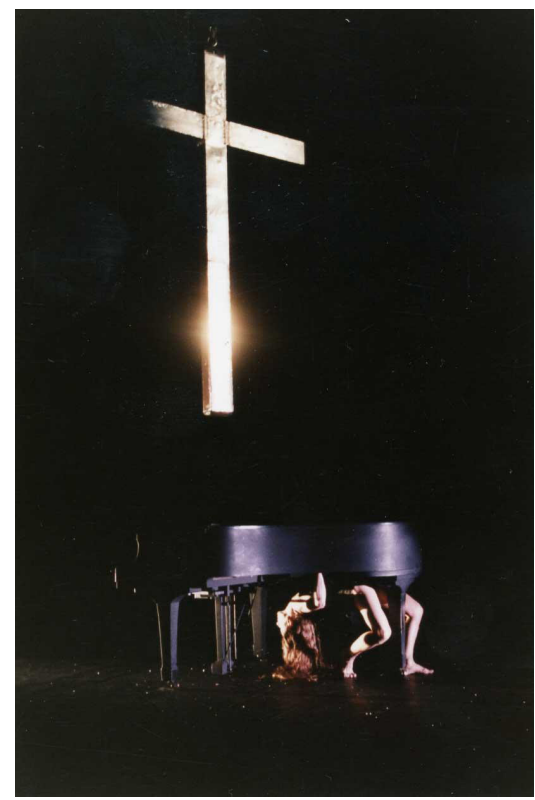

Figura 8: Ricardo y Elena (2000).

Fuente: Fundació Vinaròs, el archivo personal del artista.

12 Disponible en: https://www.youtube.com/watch?v=UsyV3lvyX74\&list=RDEME qq9tvtyxjzwAasxiqf8fg\&start_radio=1.Acceso el 24/01/2021/ 
No obstante, al reavivarse en Ricardo y Elena el pasado se inmiscuye en el presente y los dos forman una especia de amalgama, donde no hay tiempo pretérito ni presente, solo hay un tiempo único que no se va. Perdura. Santos no busca la veracidad de los hechos ni pretende hacer una terapia con aquel espectáculo, sino que suprime el tiempo y lo convierte en un tiempo festivo.

El concepto del tiempo festivo contrasta con el grado de sumisión del sujeto, sumisión a sí mismo patente en la sociedad de rendimiento descrita por Byung-Chul Han de la manera siguiente: "La sociedad del siglo XXI ya no es disciplinaria, sino una sociedad de rendimiento. Tampoco sus habitantes se llaman ya 'sujetos de obediencia', sino 'sujetos de rendimiento'. Estos sujetos son emprendedores de sí mismos" (2019, 25). Y más adelante: "En realidad, lo que enferma no es el exceso de responsabilidad e iniciativa, sino el imperativo del rendimiento, como nuevo mandato de la sociedad del trabajo tardo-moderna" (Ibidem., 29).

En las circunstancias descritas por Han es prácticamente imposible distinguir otro tiempo que no sea el que está destinado al trabajo. La idea del tiempo festivo está aniquilada en la sociedad del rendimiento porque el tiempo suprimido, que no está destinado al rendimiento, no tiene valor y, por consiguiente, está descartado. En este sentido vale la pena citar la descripción del tiempo festivo, tal como lo entiende Han:

Durante la fiesta impera otro tiempo. En ella, se ha superado el tiempo como sucesión de momentos fugaces y pasajeros. No hay ningún objetivo al cual uno tuviera que dirigirse. Justamente dirigirse es lo que hace que el tiempo transcurra. La celebración de la fiesta suprime el transcurso. A la fiesta, a la celebración del tiempo elevado, le es inherente algo imperecedero (2018a, 97). 
Al reflexionar sobre la importancia de la obra de Carles Santos para la sociedad en que vivimos, definida por Byung-Chul Han como la sociedad del rendimiento, podemos afirmar que Santos tiene el mérito de imponer un tiempo festivo en su espectáculo Ricardo y Elena y se propone compartir con el público su experiencia de duración "La experiencia dichosa de duración surge de una fusión de pasado y presente. El presente se ve conmovido, vivificado, es más, fecundado por el pasado" (Idem., 100)”.

El sonido de una cazuela arrojada contra el escenario en el final de la obra, en la que desmitifica la idea de la familia convencional manipulando su memoria individual, parece una señal que Santos hace a cualquiera de nosotros para que podamos acceder al pasado y establecer plácidamente, sin prisa, las correspondencias que nos plazcan con nuestra vida vivida, la que tenemos hoy y la que tenemos por vivir. El público de Ricardo y Elena se asombra con las visiones puestas en escena por Santos sin pudor, se siente deslumbrado por su coraje y está listo a seguir sus pasos. Podríamos decir que Santos crea un teatro erótico en el sentido que le da Byung-Chul Han, el de ser "[ ] el lugar en el que es posible la seducción, la fantasía para el otro" (Ibidem., 92). Guiándonos por el laberinto de sus fantasías en el teatro Carles Santos nos invita a que vivamos las nuestras libremente. Igual que él.

VER DE FORMA DISTINTA

Si en Ricardo y Elena Santos desafiaba la memoria de sus padres para instituir un tiempo festivo e invitarnos a vivir nuestras propias fantasías alejados 
de la orden del rendimiento, en uno de sus espectáculos más atrevidos y, por cierto, más aclamados - La pantera imperial (1997) - el artista se medía con la tradición y concretamente con su ídolo, Johann Sebastian Bach. Al recurrir al canon de la música occidental Santos quiso crear posibilidades de dar una nueva vida a aquel legado incontestable, filtradas por el espíritu de nuestra época caracterizada por la hibridación de lenguajes artísticos y la escasez de certezas consagradas. Al cuestionar la forma convencional de tratar a Bach como apenas un fenómeno musical Santos quiso abordar su obra con todas las potencialidades que la música y el teatro aportan juntos.

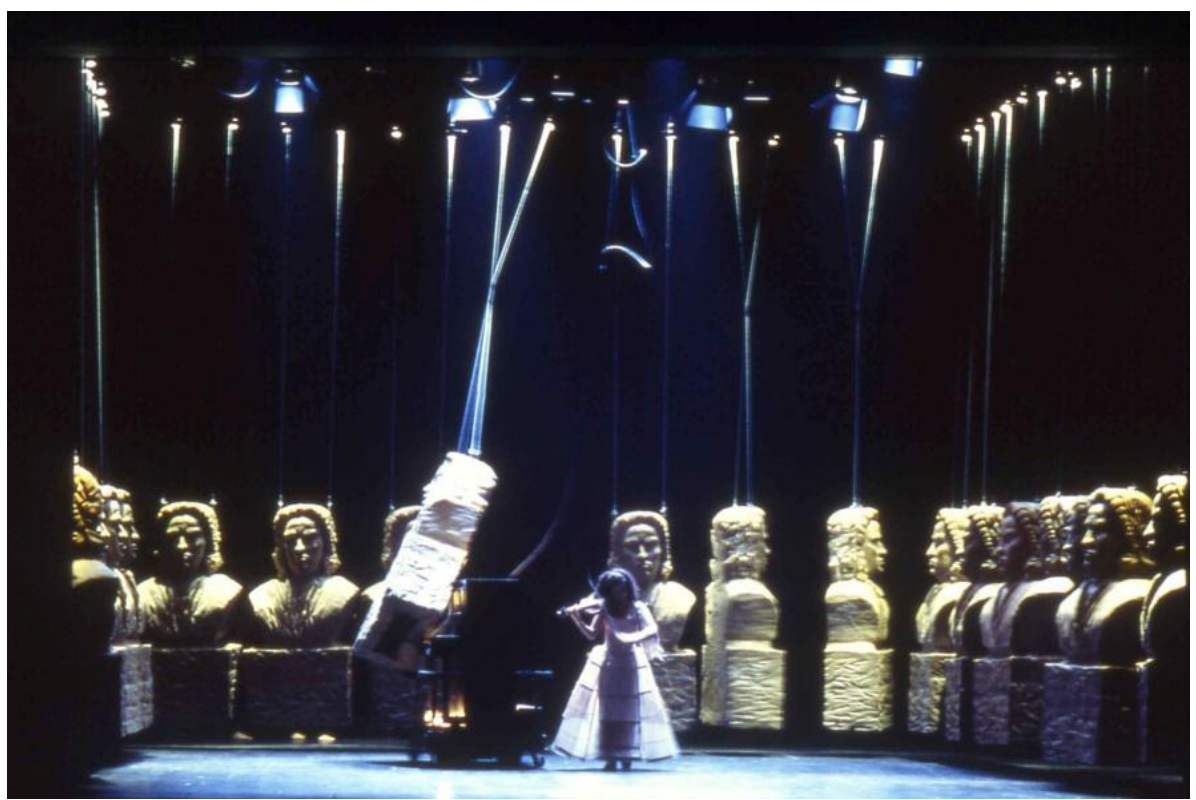

Figura 9: La Pantera Imperial (1997).

Fuente: Fundació Vinaròs, el archivo personal del artista. 
El artista ha intuido en la compleja obra de Bach una poética camuflada, que ha visualizado en el escenario a través de la secuencia de escenas configuradas como unas verdaderas batallas con la tradición que Santos no temía desafiar con el fin de revigorizarla. ${ }^{13}$ En aquella visión escénica el compositor alemán renacía como una fiera con sus facetas que nadie había puesto en escena antes. Los intérpretes se volvían notas musicales saltando en un pentagrama, competían tocando pianos, tocaban la fuga al revés para comprobar que la música tenía perfección matemática, daban pasos de flamenco zapateando al sonido de Bach o sentían vértigo al tocarlo. En un momento del espectáculo Santos se arrodillaba tocando dos pianos y en seguida se tendía en el suelo como si fuera un devoto adorando un santo. En el final de la obra dos pianos, que asumían el papel de intérpretes como si fueran cuerpos vivos, acababan perseguidos en el escenario por una pianola teledirigida ${ }^{14}$.

13 Hablo de esta cuestión más detalladamente en mi artículo: "El teatro de Carles Santos o como devorar la tradición: La pantera imperial y Ricardo y Elena". Debats - Revista de cultura, poder i societat. Vol. 134/1, Institució Alfons el Magnànim - Centre Valencià d'Estudis i d'Investigació, Valencia 2020, 197-205.

14 Disponible en: https:/www.youtube.com/watch?v=GolGHvfOLtQ. Acceso el 24/01/2021. 


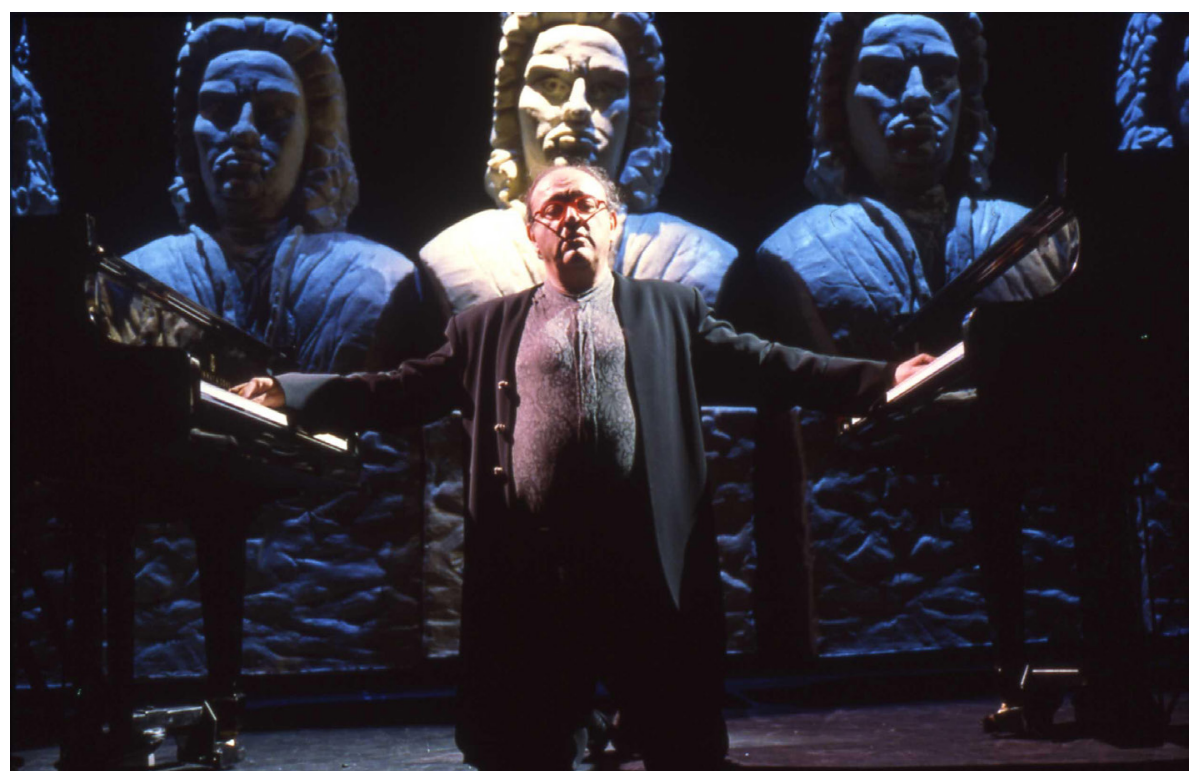

Figura 10: La Pantera Imperial (1997).

Fuente: Fundació Vinaròs, el archivo personal del artista.

Al imaginar el teatro gobernado por la música con sus potencialidades nunca vistas antes Santos estaba dispuesto a experimentar tal como lo entiende Byung-Chul Han, es decir ver de forma distinta.

No se puede ver de manera distinta sin exponerse a la vulneración. Ver presupone la vulnerabilidad. De lo contrario, solo se repite lo mismo. Sensibilidad es vulnerabilidad. La herida - así podría decirse también - es el momento de verdad que encierra el ver. Sin herida no hay verdad, es más, ni siquiera verdadera percepción (Byung-Chul Han, 2018a, 53-54).

Y aquella disposición de mostrar en el escenario lo que Santos veía de forma distinta, implicaba un cierto grado de vulnerabilidad que no le importaba 
ostentar y que le llevaba hacia una libertad creativa innegociable. En su último espectáculo -Patetisme il.lustrat (2015)-, en el que se medía con su trayectoria artística, Santos se atrevió a hacer de su trasero un instrumento de percusión y así seguir su instinto creativo sin concesiones apostando por el teatro como un espacio de comunicación entendida como un vínculo con el otro a través de las experiencias.

¡Necesito tiempo! Necesito tiempo para pensar y entender lo que me ha pasado. Estoy escribiendo lo que me ha pasado para poder leer y entender mejor lo que me ha pasado. Sigo escribiendo. [...] Necesito tiempo [...] y saber lo que ha pasado mientras escribo lo que quiero saber. Cuando deje de escribir, se acabará la obra. ${ }^{15}$

En aquella experiencia de búsqueda de sí mismo como creador, compartida con el público, Santos mostró su pasional duelo con el arte que le desafiaba, le atraía, le deseaba, le humillaba, le devoraba y volvía a darlo a luz haciéndole seguir su rastro inextinguible. El deseo era su fuerza vital y también la fuerza motora de su arte que hoy en día recobra una importancia particular en la medida en que nos remite a la idea de homo liber, el hombre soberano de sí mismo que es capaz de reconocer sus propios deseos y hacer elecciones en función de ellos. Esta cualidad humana resulta ser muy valiosa en la sociedad del rendimiento que suprime nuestra libertad de una manera sofisticada e invisible. Byung-Chul Han alerta que:

15 Fragmento del espectáculo Patetisme il.lustrat de Carles Santos, Teatre Nacional de Catalunya, Barcelona, 2015. 
La sociedad de trabajo y rendimiento no es ninguna sociedad libre. Produce nuevas obligaciones. La dialéctica del amo y el esclavo no conduce finalmente a aquella sociedad en la que todo aquel que sea apto para el ocio es un ser libre, sino más bien a una sociedad de trabajo, en la que el amo mismo se ha convertido en esclavo de trabajo. [ ] Así, uno se explota a sí mismo, haciendo posible la explotación sin dominio $(2019,45)$.

De modo que identificar sus propios deseos y seguirlos para recuperar la condición del homo liber parece una tarea ardua hoy en día para el ser humano que vive bajo el hechizo del rendimiento (Ibidem., 100). En este sentido la obra de Carles Santos adquiere suma importancia siendo un espacio, donde se celebra el deseo como una fuerza motora de la vida y del arte, al cual Santos estaba atado con un lazo imposible de romper como la bailarina del Patetisme Ilustrat que intenta moverse en el campo de zapatos rojos como amapolas. Los zapatos están pegados al suelo y ella puede probárselos poniendo sus pies dentro, pero no puede moverlos. En el inicio le cuesta mantenerse de pie, salta de un zapato a otro, varias veces corre el riesgo de caerse, se tambalea, se agacha y después se levanta. En seguida cambia de zapatos poniendo sus pies dentro, incluso se atreve a saltarles encima, se conforma con el hecho de que sea la posición de los zapatos inmovilizados que indica el rumbo de sus movimientos. Como música de fondo suena una composición de Santos de los años 70 reflejando su insolencia de aquella época, su libre opción por no obedecer normas, por transgredir lo que fuera siendo movido por su deseo que consumaba en el arte. La actriz Mónica López, una de las protagonistas de Patetisme 
Il.lustrat, comentaba la soberanía creativa de Santos especialmente valiosa en el panorama socio-cultural actual:

Yo creo que es balsámico poder trabajar con alguien que no sigue modas, que, al contrario, explica algo muy genuino suyo y, por lo tanto, es universal porque le da valor al silencio en una época donde todo es ruido. Es fantástico poder hacer esto hoy en día. ${ }^{16}$

Con las notas musicales del pasado y la imagen de la bailarina, que intenta moverse presa en el campo de zapatos rojos, Carles Santos se despedía de todo y de todos en su último espectáculo. Se murió poco tiempo después, en diciembre de 2017, de una manera inesperada en la medida en que siempre había parecido ser un sobreviviente que no hesitaría en volverse a lanzar en algún precipicio que le estaría esperando delante. Carles Santos era un artista en éxtasis que nunca dejó de sentir el placer de consumar su deseo a través del arte, que no quería comprender nada porque sabía que lo que vale la pena saber es inaprensible. Querer saber es un acto inútil, pareció decirnos Santos antes de irse definitivamente. Lo único que vale la pena es mirar y dejarse dominar por el asombro. Sin restricciones, sin palabras, sin fin. Rumbo a lo sublime.

\section{REFERENCIAS BIBLIOGRÁFICAS}

Byung-Chul Han. La expulsión de lo distinto. Barcelona: Herder, 1a ed., 2018.

16 Reportaje de la TVE sobre "Patetismo ilustrado". Disponible en: https://www.youtube.com/ watch?v=fXUC32ofSv4. Acceso el 24/01/2021. 
Byung-Chul Han. La salvación de lo bello. Barcelona: Herder, 1a ed. 2018a.

Byung-Chul Han. La sociedad del cansancio. Barcelona: Herder, 7a ed., 2019.

Ciurans, Enric. "Carles Santos, el piano a escena”. In: Serra d'Or, 667-668, 2015, 69-75.

Marín, Aurora. Carles Santos. La música posada en escena. Les principals influències en la seva obra escènica. Trabajo Final del Grado en Historia del Arte. Facultad de Geografía e Historia/Universidad de Barcelona: 2018. Disponible en: http://diposit.ub.edu/dspace/bitstream/2445/126198/1/TFG_ Mar\%C3\%ADn_L\%C3\%B3pez_Aurora.pdf. Acceso el 23/01/2021.

Ortells Agramunt, Joaquín. Análisis y catalogación de la obra de Carles Santos. Tesis doctoral. Departamento de Educación/Universitat Jaume I: 2015.

Planas, Eduard. La poesía escènica de Joan Brossa. Barcelona: Associació d'Investigació i Experimentació Teatral, Barcelona: 2002.

Rękawek, Jolanta. "Un piano fet una fera". In: Entreacte. 191, 2015, 40-46. Disponible en: http://entreacte.cat/entrades/perspectives/a-fons/un-pianofet-una-fera-el-teatre-segons-carles-santos/. Acceso el 21/12/2020.

Rękawek, Jolanta. "El teatro de Carles Santos o como devorar la tradición: $L a$ pantera imperial y Ricardo y Elena". In: Debats - Revista de cultura, poder i societat. 134/1, 2020, 197-205.

Ruvira, Josep. El caso Santos, València: Mà d'obra, 1996.

Ruvira, Josep. “Carles Santos. Codi o estigma?”. In: Quimera, 168, 1998, 31-37.

Ruvira, Josep. Música y representación: los desafios artísticos de Carles Santos. Valencia: Institut Valencià de la Música i Institució Alfons el Magnànim, 2008.

Salvat, Ricard. "Panorama general del teatro catalán (1939-2008)". In: Assaig de teatre: revista de l'Associació d'Investigació i Experimentació Teatral, 68, 2008, 195-206. 
Santos, Carles. Textos escabetxats. Barcelona: March Editor, 2006.

Salvat, Ricard. "Val la pena saber el que no podem saber?”. Entrevista con Carles Santos realizada por Jolanta Rękawek y Enric Ciurans. Barcelona: Universitat de Barcelona, 02/06/2014, disponible en el archivo de los autores y depositada en la Fundació Vinarós.

\section{CATÁlOGOS:}

Carles Santos. Catálogo da exposición. Castellón: Espai de l'Art Contemporani de Castellò, 25/05 - 05/1, 1999.

Guerrero, Manuel (ed.). Carles Santos. Visca el piano!. Catálogo de la exposición. Barcelona: Generalitat de Catalunya, Fundació Miró, 2006.

SIMPOSIOS Y JORNADAS:

DD.AA. L'accionisme. En els límits de l'art contemporani. Jornada organizadas por el Grup de Recerca en Estètica General i Antropològica (GREGA) de la Universitat de Barcelona, con la colaboración del Institut del Teatre de la Diputació de Barcelona. Publicacions i Edicions de la Universitat de Barcelona, 2013.

Programas de espectáculos:

Santos, Carles. Figasantos-Fagotrop, missatge al contestador: soparem a les nou. (Teatro Poliorama, 1996).

Santos, Carles. La pantera imperial. (Teatre Lliure, 1997).

Santos, Carles. Ricardo y Elena. (Teatre Nacional de Catalunya 2000).

Santos, Carles. Sama samaruck suck suck (Teatre Nacional de Catalunya, 2002).

Santos, Carles. El fervor de la perseverança. (Teatre Lliure, 2006). 
Santos, Carles. Shubertnacle humits. (Teatre Lliure, 2012).

Santos, Carles. Patetisme il.lustrat. (Teatre Nacional de Catalunya, 2015).

Programas de RADIO Y TELEVISIÓN:

"Imprescindibles - Energía Santos (Carles Santos)", programa de la TVE, La 2, 11/12/2017. Disponible en: http://www.rtve.es/alacarta/videos/imprescindibles/ imprescindibles-carlessantos/2787834/. Acceso el 26/01/21.

“El Matí de Catalunya Ràdio”. Disponible en: https://www.youtube.com/ watch?v=zlYQG9301qo. Acceso el 20/03/24.

"La culpa fue de Joan Brossa", reportaje de la TVE. Disponible en: https://www. youtube.com/watch?v=kY4106zKmTc\&t=319s. Acceso el 25/01/2020.

Reportaje de la TVE sobre "Patetismo ilustrado". Disponible en: https://www. youtube.com/watch?v=fXUC32ofSv4. Acceso el 24/01/2021.

Toni Puntí entrevista a Carles Santos en TV3. Disponible en: https://www.youtube. com/watch?v=M8wDZcJXl3M. Acceso el 25/01/21.

"Imprescindibles - Brossa, poeta transitable". Documental de la TVE, La 2a. Disponible en: https://www.youtube.com/watch?v=j_FJShS-y2s. Acceso 24/01/2021.

Links de las obras de Carles Santos:

https://www.youtube.com/watch?v=P0d2AQHScss, "Minimalet sur mer" (1984). Acceso el 24/01/2021.

https://vimeo.com/404575588, Anem, anem, anem a volar (1982). Acceso el 24/01/2021. Anem, anem, anem a volar (1982. 
https://www.youtube.com/watch?v=GolGHvfOLtQ, los fragmentos de La pantera imperial. Acceso el 24/01/2021.

https://www.youtube.com/watch? $v=j I 3 W Z a K t K j s \& l i s t=R D j I 3 W Z$ aKtKjs\&index=1, los fragmentos de Brossalobrossotdebrossat (2008). Acceso el 24/01/2021.

https://www.youtube.com/watch?v=qpNYppyVPdM, los fragmentos de Sama samaruck suck suck. Acceso el 25/01/2021.

https://www. youtube.com/watch?v=UsyV3lvyX74\&list=RDEME qq9tvtyxjzwAasxiqf8fg\&start_radio=1, el fragmento de Ricardo y Elena. Acceso el $24 / 01 / 2021$.

https://www.youtube.com/watch?v=I3IKLA4T054, Carles Santos presenta su último disco "Lo bo ve per baix" en el Centro de Arte Santa Mónica en Barcelona. Acceso el 24/01/2021. 
